\title{
CONTRIBUIÇÕES DA ARTE E DO PROFESSOR ARTETERAPEUTA PARA A EDUCAÇÃO INCLUSIVA
}

\section{CONTRIBUTIONS OF ART AND ART THERAPIST TEACHER FOR INCLUSIVE EDUCATION.}

DOI: http://dx.doi.org/10.5965/1984317813022017136

Camila de Carvalho Vieira - UEL

\begin{abstract}
RESUMO
Ao longo do tempo tem-se constatado a importância das práticas artísticas para o desenvolvimento da sensibilidade, da socialização e educação dos indivíduos. Dentre os diferentes públicos-alvo da educação, os alunos da educação especial poderiam se beneficiar da utilização da arte como viés terapêutico, contribuindo para a educação, socialização e inclusão ao ambiente escolar. Desta forma, este trabalho, elaborado a partir de revisões bibliográficas, teve por objetivo discutir a importância do professor de arte e a inserção de práticas terapêuticas na intervenção com alunos público alvo da educação especial. Discutiuse sobre a importância das práticas artísticas do professor na educação inclusiva, oferecendo sugestões de atividades de arteterapia que poderiam ser aplicadas. Destacou-se que tais práticas poderiam estimular diversas funções e habilidades se inseridas com o propósito de perceber as habilidades e necessidades de cada educando, para que seja possível fazer as adaptações aos recursos e estratégias de ensino e, assim, facilitar e propiciar a aprendizagem.
\end{abstract}

Palavras-Chave: Professor de arte - Educação inclusiva - Arteterapia.

\begin{abstract}
Over time it has been verified the importance of art practices for the development of sensitivity, socialization and education of subjects. Among the different target audiences of education, students of special education would benefit from art as therapeutic bias, contributing in his education, socialization and inclusion to the school environment. Thus, this study, based on bibliographical reviews, aimed to discuss the importance of art teacher and the inclusion of therapeutic practices in the intervention with students special education target audience. It was discussed the value of the teacher's artistic practices in inclusive education, offering suggestions of art activities to be applied. It was pointed out that such practices could stimulate different functions and skills if inserted with the purpose to perceive the needs and skills of each learner, making possible the adaptation of the resources and teaching strategies to facilitate learning
\end{abstract}

Key-words: Art teacher - Inclusive educacion - Art therapy. 


\section{INTRODUÇÃO}

Desde os tempos pré-históricos, os homens vêm se apropriando da arte e das imagens como forma de comunicação e representação artística/social, pois, o simples fato de registrar animais na parede da caverna já era uma configuração de diálogo e linguagem (PROENÇA, 2000). Nas suas marcas, traduziram sua visão de mundo e suas inquietações em imagens, comunicando-se com o outro e com o seu meio, a fim de criar universos de representação nos quais ações e relações sociais podem ser lidas e compreendidas ainda hoje.

Do período rupestre à contemporaneidade, a arte tem representado um papel importante na sociedade e na cultura. Porém, o que as diferem de lá para cá, são as mudanças que ocorreram na forma de comunicação social, assim como, no modo de compreensão a respeito das atribuições destinadas às obras de arte. Sabe-se que as manifestações artísticoculturais tornaram-se, através dos séculos, a expressão mais permanente de criação humana, pois, não há civilização sem expressão artística e esta é uma fórmula genuína que tem o poder de distinguir culturas, conceitos, crenças e modos de pensamento.

Atualmente, considera-se que a arte compreende um universo amplo de múltiplas formas de linguagem, como as artes plásticas, a música, dança, teatro (PROENÇA, 2000), o que pode vir a oferecer diferentes formas de comunicação, oportunidades de expressão, meio de autoafirmação, desenvolvimento da criatividade, favorecendo assim a socialização e estimulando o desenvolvimento psicomotor das pessoas, com ou sem deficiências, contribuindo igualmente com a aprendizagem escolar.

Estudos apontam que a arte também pode se portar como sendo um meio terapêutico efetivo, promovendo a saúde psíquica e a qualidade de vida, de forma criativa e dinâmica. (SILVEIRA, 2001). A arte, por exemplo, é capaz de causar efeitos positivos e surpreendentes no acompanhamento de pacientes/alunos para a reabilitação de disfunções físicas e mentais, através de um processo terapêutico chamado: arteterapia, que é uma prática responsável por fazer com que o indivíduo entre em contato com seus conteúdos internos e muitas vezes inconscientes. 
A arteterapia usa a arte como meio de expressão pessoal para comunicar sentimentos, em vez de ter como objetivo produtos finais esteticamente agradáveis a serem julgados segundo padrões externos. Esse meio de expressão é acessível a todos, não apenas aos que tem talentos artísticos. (LIEBMANN, 1994, p. 18).

As atividades de arte no processo de intervenção terapêutica são utilizadas como instrumentos de diagnóstico e tratamento. A arteterapia age através da estimulação da expressão artística, do desenvolvimento da criatividade, favorecendo a expressão dos sentimentos e a reorganização interna do indivíduo (GOLDSCHMIDT, 2004). O fazer artístico poderá estimular diversas funções e habilidades integrando os sistemas: sensorial, motor, emocional e cognitivo. Através da ampliação, percepção e exteriorização de sentimentos, a arte é capaz de despertar a motivação e resgatar a autoestima daqueles que a utilizam.

Ao estimular diversas funções e habilidades, as práticas artístico-terapêuticas podem ser inseridas na educação especial com o propósito de perceber as habilidades e necessidades de cada educando, para que seja possível fazer as adaptações aos recursos e estratégias de ensino e, assim, facilitar e propiciar a aprendizagem. Através das modalidades expressivas o ser humano desenvolve um processo intenso de conhecimento de si próprio, do outro e do mundo ao qual está inserido, reconhecendo suas limitações e descobrindo seus talentos.

$\mathrm{Na}$ atualidade, inúmeros trabalhos vêm salientando a importância da produção artística, no âmbito das necessidades educacionais especiais como, por exemplo, cegueira, surdez, autismo, deficiência intelectual, entre outros, num parâmetro social, formal ou cognitivo. Ainda que raro, estes trabalhos vem ganhando espaço no campo acadêmico e salientando a importância da pesquisa nesta vertente pouco conhecida dentro das artes visuais.

A literatura existente em arte e educação tem apontado a importância da adaptação e adequação de recursos e estratégias para o ensino do aluno com deficiência. A disciplina de arte, juntamente com as demais, deve adaptar seus currículos para que possam receber os alunos público alvo da educação especial - (PAEE) com o desígnio de atendê-los de forma digna e eficaz. Sabe-se que a educação, de forma geral, deve considerar a pessoa com necessidades educativas especiais enquanto ser humano, sujeito histórico, social, cultural e 
também simbólico. O aluno público alvo da educação especial apreende, mas é necessário que o professor saiba o que propor e em que situações devem elaborar atividades, dentro de suas especificidades.

Como a arte e o ensino de arte se inserem na educação inclusiva? Revendo o histórico do ensino de arte, da arte-educação nas escolas também é possível constatar progressos e recuos. Em muitas escolas, talvez na maioria delas, não exista um professor graduado em artes visuais ou capacitado para essa área. A partir destes apontamentos, faz-se necessário repensar: será que as práticas artísticas ou arteterapêuticas podem beneficiar os alunos inseridos na educação inclusiva? Nesse sentido, o objetivo deste artigo será discutir a importância do professor de arte e a inserção de práticas terapêuticas para alunos público alvo da educação especial. Para tanto, esta pesquisa pautou-se em revisões bibliográficas, oriundas através de livros, artigos científicos e referências via internet.

\section{REVISÃO DA LITERATURA}

\subsection{A Educação Especial e a Formação do Professor}

O cenário educacional brasileiro atual traz como desafio aos educadores de todos os níveis escolares as propostas para uma educação inclusiva. Os pressupostos da Inclusão Escolar vêm se solidificando com a Declaração de Salamanca (1994) e com a promulgação da Lei 9394/96 - Lei de Diretrizes e Bases da Educação Nacional (1996) que estabelece regulamentações com vistas a garantir o oferecimento de um atendimento educacional ao aluno público alvo da educação especial nos níveis de educação regular. A Lei 9394/96 aponta ainda, elementos que garantam a abertura de todas as escolas para o processo de ensino/aprendizagem desses alunos. Desde então, práticas pedagógicas e sociais vêm sendo construídas com o objetivo de contemplar essa proposta educacional. Neste movimento, a luta pela ampliação do acesso e da qualidade da educação das pessoas portadoras de deficiência culminou, no início dos anos 90, com a proposta da educação inclusiva, hoje amparada e fomentada pela legislação em vigor, e determinante das políticas públicas educacionais a nível federal, estadual e municipal (FERREIRA; GLAT, 2003). 
A "Declaração de Salamanca" (1994) que entre outros pontos, propõe que as crianças e jovens deficientes devem ter acesso às escolas regulares, que a elas devem se "adequar", pois tais escolas constituem os meios mais capazes para combater as atitudes discriminatórias. A premissa básica desse conceito é que pessoas com deficiências têm o direito de usufruir as condições de vida o mais comuns ou normais possíveis na comunidade onde vivem, participando das mesmas atividades sociais, educacionais e de lazer que os demais.

As escolas devem acolher todas as crianças, independentemente de suas condições físicas, intelectuais, sociais, emocionais, linguísticas ou outras. Devem acolher crianças com deficiência e crianças bem dotadas; crianças que vivem nas ruas e que trabalham; crianças de populações distantes ou nômades; crianças de minorias linguísticas, étnicas ou culturais e crianças de outros grupos ou zonas desfavorecidas ou marginalizadas (BRASIL, 2006, p. $18)$.

"O portador de necessidades intelectuais pode se integrar na sociedade" tornou-se, assim, a matriz política, fillosófica e científica da educação especial. Este novo pensar sobre o espaço social das pessoas com deficiência resultou em uma transformação radical nas políticas públicas, nos objetivos e na qualidade de serviços de atendimento a esta clientela.

Segundo o documento,

Todas as crianças deveriam aprender juntas, independentemente de quaisquer dificuldades ou diferenças que possam ter. As escolas inclusivas devem reconhecer e responder às diversas necessidades de seus alunos, acomodando tanto estilos como ritmos diferentes de aprendizagem e assegurando uma educação de qualidade a todos através de currículo apropriado, modificações organizacionais, estratégias de ensino, uso de recursos e parceiras com a comunidade. (DECLARAÇÃO DE SALAMANCA, 1994, p.21).

O conceito de educação inclusiva, de acordo com as Diretrizes Curriculares Nacionais para a Educação Especial (BRASIL, 2001), implica uma postura da escola comum que propõe no projeto político-pedagógico, no currículo, na metodologia de ensino, na avaliação e na 
atitude dos educadores, ações que favoreçam integração social e a sua opção por práticas heterogêneas.

Porém, ao mesmo tempo em que se preza pela inclusão dos alunos público alvo da educação especial, faz-se necessário refletir e reestruturar a formação daqueles que serão os principais responsáveis por essa "inserção do aluno" dentro das escolas regulares, ou seja, repensar a prática pedagógica do professor. Em meio a tantas contradições, o educador possui um papel de destaque no sucesso da inclusão. Sua dedicação, preparo e desejo são fundamentais, pois sabe-se que seu cotidiano dentro de sala de aula irá ser totalmente modificado para que possa atender aos alunos público alvo da educação especial, e na maioria das vezes, este professor não recebe nenhum tipo de preparo especializado para recebê-los.

No momento histórico atual deve-se refletir sobre como ocorre à formação dos profissionais que atuam no campo educacional, particularmente no que se refere às diretrizes curriculares para formação de professores da Educação Básica e da Educação Inclusiva. São inúmeros os discursos que constituem a escola e seu currículo no sentido de adequá-los a nova legislação e a nova realidade social que se impõe. O desafio que se coloca para os educadores é construir um espaço escolar onde a diferença, de qualquer natureza, possa existir.

Segundo Guattari (1992), crianças com deficiência necessitam de ações mediadas, dos agentes mediadores, da postura de mediação do professor. Se o processo de transmissão de ensinamentos não fica restrito às escolas, mas se dilui pelas malhas da rede social, é de grande importância que se repense todo o processo de formação de professores em diferentes níveis, para atuar no contexto dessa sociedade do conhecimento. O educador deve estar preparado para o principal desafio que se lhe coloca hoje, que é o de produzir novas potencialidades.

Autores como Mazzota (2003), Omote (2003) e Ortiz (2003), apontam para a transformação da postura dos educadores envolvidos no processo de ensino/aprendizagem de alunos público alvo da educação especial em contexto regular, como uma das principais ações rumo à consolidação da proposta de inclusão para a educação. Há a necessidade de se mudar o pensamento dos educadores quanto ao objetivo dessa proposta educacional, quanto à concepção de aluno, ou seja, a quem esses educadores vão ensinar e o porquê dessa educação, enfatizando na precisão de se investir em processos de formação desses educadores. 
No percurso da mediação, cabe aos professores, bem como, a comunidade escolar, de forma geral, se adaptar a realidade que estão inseridos, buscando cursos de formação complementar e capacitação para que possam aprimorar suas práticas educacionais no intuito de atender a demanda da expansão da educação especial. Em contrapartida, é evidente que os órgãos competentes precisam urgentemente criar serviços de apoio para auxiliar esses profissionais e, as universidades, por sua vez, reestruturar os cursos de pedagogia e as demais licenciaturas afim de que possam preparar os profissionais para lidar com a Educação Inclusiva.

Não se pode negar a importância dos conteúdos didáticos para a aprendizagem do aluno, mas de nada vale simplesmente transmitir esses conteúdos e acreditar que seu papel como educador está feito. O professor que trabalha em um ambiente inclusivo deve fazer mais do que repassar conteúdos, deve sair do comodismo e estar disposto a envolver-se, criando mecanismos que o auxiliem neste processo. De acordo com as palavras de Boato (2007, p.52), “da mesma forma eu, como educador, cheio de conteúdos, de conhecimentos, de técnicas, de métodos, nada conseguirei com meus alunos se me mantiver neutro, não envolvido, se não houver amor".

Tendo em vista as contradições sociais presentes no cotidiano escolar e as consequentes mudanças nas concepções de trabalho, cresce a necessidade do resgate do significado das ações do professor, visto que o trabalho possui um valor social e pessoal. As mudanças e os problemas enfrentados provocam nos professores, muitas vezes, sensações de impotência diante dos novos desafios. Por essa perspectiva, o educador pode ter todo o recurso técnico e apoio em sala de aula, pode dominar o conteúdo que pretende trabalhar com os alunos e pode até mesmo querer trabalhar com as crianças com deficiências. Entretanto, se esse profissional não acreditar no valor e na importância de sua atuação, se ele não se sentir capaz de promover uma transformação, a menor que seja, a possibilidade de ele realizar um atendimento educacional promotor de processos de ensino/ aprendizagem será menor.

Para que a aprendizagem significativa aconteça, o professor precisa se envolver e vivenciar a realidade do aluno; precisa atender as especificidades decorrentes de determinadas deficiências priorizando o trabalho conjunto com a família, escola e comunidade, criando estratégias didático-metodológicas que promovam a aprendizagem e favoreçam o acesso ao 
conhecimento, aos instrumentos materiais e culturais produzidos pela comunidade. Com a educação inclusiva, a mediação na aprendizagem adquire um caráter de grande importância, uma vez que situam três questões imprescindíveis ao processo de construção do conhecimento: o aluno, como o sujeito que apreende; o professor como mediador, a cultura, os signos como ferramentas a serem empregadas. O princípio que regula a dinâmica implícita nessa trama conceitual é a interação social. Trata-se de um modelo pertinente em tempos de educação inclusiva, onde a interação é o princípio essencial (VYGOTSKY, 1984).

Para Proença (2000), fazer arte e pensar sobre o trabalho artístico que realiza, assim como a arte que é, e foi concretizada na história, podem garantir ao aluno uma situação de aprendizagem conectada com os valores e os modos de produções artísticas nos meios socioculturais. Ensinar arte em consonância com os modos de aprendizagem do aluno significa, então, não isolar a escola da informação sobre a produção histórica e social da arte e, ao mesmo tempo, garantir ao aluno a liberdade de imaginar e edificar propostas artísticas pessoais ou grupais com base em intenções próprias.

A arte como instrumento de inclusão social pode e deve ser vista como fator de complemento nas diversas formas de desenvolver aprendizagens uma vez que a linguagem visual permite que o aluno público alvo da educação especial tenha a possibilidade de uma comunicação diferente da verbal, com a qual também é possível expressar o que pensa e o que sente.

\subsection{A Importância da Arte para a Educação Especial}

O ensino de arte possui características específicas que o diferencia das demais áreas do conhecimento, pois trabalha não só com o desenvolvimento cognitivo do ser humano como também seu desenvolvimento sensível; instiga a expressão movida pela emoção, intuição e o pensar sobre aquilo que se exterioriza.

A arte é uma grande estratégia para se caminhar rumo ao desenvolvimento expressivo e representacional da criança, e, por isso mesmo, precisa ser mais valorizada dentro da escola, não somente como hora de desenhar e pintar, mas como uma disciplina curricular importante para o desenvolvimento das crianças com deficiência. 
Segundo os Parâmetros Curriculares Nacionais:

\begin{abstract}
A educação em arte propicia o desenvolvimento do pensamento artístico, que caracteriza um modo particular de dar sentido às experiências das pessoas: por meio dele, o aluno amplia a sensibilidade, a percepção, a reflexão e a imaginação de aprender, pois a arte envolve, basicamente, fazer trabalhos artísticos, apreciar e refletir sobre eles. Envolve também, conhecer, apreciar e refletir sobre as formas da natureza e sobre as produções artísticas individuais e coletivas de distintas culturas e épocas. Para tanto, a escola deve saber aproveitar a diversidade de recursos humanos e materiais disponíveis na comunidade em que ela esteja inserida, a fim de que o aluno, ao longo da escolaridade, tenha a oportunidade de vivenciar o maior número de formas de arte (BRASIL, 1997, p.15).
\end{abstract}

A atividade artística, seja qual for, abrange a habilidade de usar o cérebro para alterar, renovar, recombinar o aspecto da vida, da experiência acumulada. Implica em sentir o mundo com vitalidade e fazer um novo uso do que se percebeu. Na concepção de (CARDOSO, 1997), a Arte, na educação, dá espaço ao desenvolvimento artístico: a sensibilidade, a reflexão, a percepção e a imaginação.

A arte se mostra importante tanto no currículo como na vida, pois resgata e trabalha no afloramento e qualificação da sensibilidade no ser humano, sendo assim uma condutora da humanização dos mesmos, e isso pode ser constatado principalmente no viés da Educação Inclusiva (RUTZ, 2010). Neste contexto, pode-se observar que ela oferece aos alunos a capacidade de se expressar livremente, criar e proporcionar a experimentação de possibilidadese construção de significações para a contextualização de seu cotidiano, proporcionando aos mesmos uma atividade prazerosa e um campo rico para o desenvolvimento expressivo e social.

Costa (2000) evidenciou a importância de trabalhar a arte visual junto a crianças com "deficiência", no sentido de promover a motivação e a criatividade, contribuindo para a construção de sujeitos mais sensíveis, prontos para descobrir suas habilidades e talentos. De acordo com o autor é através da disciplina de arte que a criança expressa seus sentimentos, desejos, suas fantasias e ansiedades. Assim, a arte é um importante trabalho educativo, pois estimula a inteligência e contribui para a formação da personalidade do indivíduo. 
Nas propostas de trabalho oferecidas nas aulas, o aluno tem a possibilidade de exteriorizar seus sentimentos, através de representações em desenhos e outros trabalhos práticos, bem como, em exercícios de expressão corporal e auditivo, o que facilita para o professor a identificação das maiores dificuldades enfrentadas por seus alunos, para que possa auxiliá-los. $\mathrm{O}$ ensino de arte nas escolas possibilita aos alunos público alvo da educação especial o despertar da criatividade, oferecendo um contato constante com a realidade e a fantasia, propiciando o desenvolvimento do pensamento artístico e da percepção estética.

Assim, a educação utilizando a arte como ferramenta, se torna um processo dinâmico e contínuo que deve ser utilizado para facilitar a compreensão dos alunos deficientes considerando-os enquanto ser humano, histórico, social, cultural e também simbólico. $\mathrm{O}$ aluno público alvo da educação especial apreende, mas é necessário que o professor saiba o que propor e em que situações devem elaborar atividades, dentro de suas especificidades, habilidades e dificuldades. Para Proença (2000, p. 59):

Cabe ao professor escolher os modos e recursos didáticos adequados para apresentar as informações, observando sempre a necessidade de introduzir formas artísticas, porque ensinar arte com arte é o caminho mais eficaz. Em outras palavras o texto literário, a canção e a imagem trarão mais conhecimentos ao aluno e serão mais eficazes como portadores de informações a se exercitar nas práticas de aprender a ver, observar, ouvir, atuar, tocar e refletir sobre elas.

Segundo Read (1976), a arte na escola vem remover barreiras à aprendizagem junto aos indivíduos com deficiência, pois funciona como forma de redescoberta, pelo professor e pelo aluno, onde deve observar e registrar dados para, depois de avaliados, servirem para a formulação de teorias oriundas da prática. Ensinar arte em consonância com os modos de aprendizagem do aluno significa, então, não isolar a escola da informação sobre a produção histórica e social da arte e, ao mesmo tempo, garantir ao aluno a liberdade de imaginar e edificar propostas artísticas pessoais ou grupais com base em intenções próprias.

Dada a importância e a necessidade da arte para finalidade pedagógica, Silveira (2001) afirma que ao se dedicar a uma atividade criadora, artística, a pessoa melhora sua autoestima, baixa seu nível de angústia, de estresse e de ansiedade, possibilitando lidar de forma mais 
saudável e equilibrada com as dificuldades que se deparam no dia a dia. Sendo assim, o trabalho no recinto escolar com arte, para os alunos inclusos, poderá ser estimulado para que funcione como sendo um diagnóstico terapêutico.

A arte pode ser considerada como uma forma de terapia de quadros clínicos previamente diagnosticados, tornando-se uma área interdisciplinar relevante na formação profissional dos terapeutas. É hoje cientificamente reconhecido o valor que tem a atividade artística para o desenvolvimento pessoal enquanto processo de libertação, comunicação, crescimento e auto descoberta (BARBOSA, 2005).

O uso da arte para atividades terapêuticas mostrou-se pertinente dentro da educação especial. Silva (2005) aponta que, por meio da articulação de conteúdos de Psicologia, Arte e Educação, é possível criar um outro olhar sobre a própria pessoa e sobre o mundo que o cerca. Assim, a arte pode contribuir para a valorização da diferença e individualidade dos sujeitos envolvidos, auxiliando na promoção dos processos de aprendizagem.

Refletir sobre a importância das escolas especiais apresentarem um professor arteterapeuta e as contribuições e benefícios que esta prática de intervenção artística pode proporcionar na educação e socialização dos alunos inclusos é um dos principais objetivos desta pesquisa.

\subsection{Contribuições da arterarapia nas aulas de Artes Plásticas}

Existem muitas possibilidades de conceituar arteterapia. Uma delas é considerá-la como uma disciplina híbrida baseada principalmente na junção das áreas da arte e da psicologia. De acordo com Ciornai (2004), é o termo que designa a utilização de recursos artísticos em contextos terapêuticos. É um caminho através do qual cada indivíduo pode encontrar possibilidades de expressão para elaborar e redimensionar suas dificuldades da vida a partir de técnicas e materiais artísticos. Enquanto a arte educação ensina arte, a arteterapia possui a finalidade de propiciar mudanças psíquicas, assim como a expansão da consciência, a reconciliação de conflitos emocionais, o autoconhecimento e o desenvolvimento pessoal, no intuito de proporcionar a resolução de conflitos interiores. 
Partindo do princípio de que é muito difícil para um paciente ou aluno conseguir falar sobre suas desordens pessoais, a arteterapia surge com a função de fazer com que essas “expressões individuais" possam ser delineadas e analisadas, sempre buscando obter uma maior compreensão do sujeito. Por ser uma técnica de atuação sutil e por combinar elementos expressivos e criativos, a arteterapia pode ser aplicada a pessoas de todas as idades, de crianças a idosos, individualmente ou em grupos. Esta prática é muito eficaz em casos de dependência química, hiperatividade, deficiência auditiva e visual (dentre outros problemas físicos), doenças degenerativas como o alzheimer, doenças mentais e em casos de dificuldade de comunicação verbal e intelectual.

No Brasil, esta nova possibilidade de criação artística se desenvolve a partir do trabalho de Nise da Silveira, psiquiatra brasileira que propôs a reformulação do tratamento dos doentes mentais, criando em 1946 a sessão terapêutica ocupacional no Centro Psiquiátrico Pedro II, no Rio de Janeiro. Fundou o Museu de Imagens do Inconsciente, em 1952, reunindo material produzido nos ateliês de pintura e modelagem da seção terapêutica ocupacional. Mais tarde, em 1956, com a colaboração de amigos, abre a clínica de reabilitação para egressos de instituições psiquiátricas, a Casa das Palmeiras. Ela foi também responsável pela introdução da psicologia Jungiana no país.

Silveira (2001) defendeu o estudo com doentes mentais por meio da pintura, por acreditar que é possível revelar coisas do inconsciente que não eram relatadas pelos doentes nas conversas com os terapeutas. Afirmava que as imagens falam por si, traduzem uma linguagem mítica que vem das profundezas da psique. Foi por estes motivos que a autora resolveu utilizar a arte como uma forma de terapia, criticando a psiquiatria vigente. Através dos ateliês terapêuticos, incentivava seus pacientes a descobrir por si próprio a significação de suas criações, bem como, a trabalhar dentro de si uma possível cura e reflexão sobre suas patologias utilizando modalidades artísticas expressivas.

Nas sessões atuais de arteterapia, podem-se realizar trabalhos de pintura, colagem, modelagem, bordado, desenho, música, teatro, dança, jogos, contação de histórias, entre outros, com o objetivo de possibilitar e facilitar a comunicação entre professor/terapeuta com o paciente/aluno. A finalidade é proporcionar o bem estar físico/mental/espiritual através do fazer artístico; bem como, "interpretar" a obra de arte realizada por determinada pessoa no 
intuito de contribuir para o desbloqueamento de conteúdos psíquicos traumáticos (FERNANDES, 1990).

Através da atividade com arte o sujeito transforma a realidade e a si mesmo, promovendo o desabrochar da percepção, da organização e ordenação do seu pensamento, possibilitando a compreensão do momento circunstancial, bem como da dimensão de si mesmo (URRUTIGARAY, 2004). Os benefícios da arteterapia no dia-a-dia, seja na vida cotidiana ou na escola atingem praticamente todas as pessoas, uma vez que o trabalho artisticoterapeutico gera introspecção, concentração e reflexão deixando as pessoas mais calmas, atentas, com os olhos focados em sua produção, acompanhando criteriosamente o resultado de cada passo realizado. O fazer artístico possibilita um desbloqueio de emoções conscientes permitindo ao sujeito que retome uma nova força vital bastante benéfica para seu bem estar.

Muitos fatores determinam o funcionamento da aplicação da arteterapia enquanto elemento facilitador da aprendizagem. O mundo da arte combinado com a terapia pode ser usado para ajudar o aluno a exteriorizar tanto seus afetos quanto suas possibilidades, facilitando seu processo de aprendizagem e construção do conhecimento. Através das práticas terapêuticas é possível trabalhar, em primeiro lugar, a autoestima baixa das crianças, o baixo rendimento escolar, os problemas de indisciplina, socialização, relacionamento e insegurança. Desta forma, práticas e vivências são utilizadas para trabalhar bloqueios de aprendizagem e construção dos conceitos.

São por estes motivos que dentro das escolas, principalmente aquelas de educação inclusiva, seria importante ter um profissional da área de artes capacitado para trabalhar técnicas artísticas baseadas no conceito da arteterapia. Além de ensinar os conteúdos préestabelecidos da disciplina e experimentar diferentes materiais e linguagens, este docente poderia contribuir para que os educandos possam expressar, por meio de modalidades artísticas diversificadas, seus conflitos interiores, na tentativa de superá-los e obter uma melhor qualidade de vida.

Ao acolher o indivíduo e disponibilizar um ambiente em que ele possa criar arte e falar sobre o seu processo de criação, a arteterapia possibilita: aumentar a autoconsciência e autoestima; ajuda a desenvolver habilidades cognitivas e sociais; auxilia no estímulo da 
imaginação e da criatividade; ajuda a expressar sentimentos difíceis de verbalizar; etc. Para que estas possibilidades aconteçam, é necessário que se avalie o material terapêutico para cada aluno, pois estes podem auxiliar de maneira mais rápida e direta nos conflitos internos e inconscientes de cada indivíduo. Sendo assim, seria importante que os docentes reelaborem novas propostas curriculares que possam facilitar a troca de experiências com alunos, na tentativa de promover avanços a ambas às partes.

Para Allessandrini (2004), uma das possibilidades de se trabalhar com atividades artísticas no ambiente escolar seria através das oficinas criativas, ou seja, atividades em grupo ou individuais que tem por finalidade promover o desenvolvimento das dimensões afetivas e cognitivas do sujeito nas diferentes relações durante a realização de um projeto artístico. As vivências e atividades expressivas ajudam a pessoa a desenvolver recursos que lhe permitem lidar com as questões da sua vida e de seu momento de desenvolvimento de uma maneira mais integrada, expandindo seus potenciais. Como resultado final, cada participante tem a oportunidade de conhecer vários materiais e técnicas, proporcionando-lhe um maior conhecimento de si, do outro e do mundo que o cerca, enriquecendo e ampliando suas experiências de vida.

A seguir serão dados alguns exemplos de atividades artísticas realizadas através de oficinas criativas que se utilizam da arteterapia como fonte de criação e inspiração.

- Elaboração de retratos e autorretratos: Desenvolve o autoconhecimento, autoestima, conhecimento maior do real.

- Manipulação de objetos com os olhos vendados, e verbalização de seus atributos: Trabalha a representação mental e discriminação de estímulos táteis.

- Expressão oral, plástica, corporal: Tem fundamental importância no desenvolvimento global.

- Pintura a dedo: Atividades artísticas como estas favorecem o desenvolvimento afetivo, especialmente por facilitarem a livre-expressão e assegurarem o equilíbrio emocional. 
- Argila ou massa de modelar: Ao manipularem, os alunos desenvolvem a coordenação motora fina e a relação com o espaço.

- Atividades de recorte e colagem: Além de contribuir para o desenvolvimento cognitivo, trabalha a motricidade fina e a imaginação.

- Dobraduras: Desenvolve a criatividade, a atenção e a coordenação motora.

- Jogos com regras: Trabalha o raciocínio, atenção, antecipação de situações através de diferentes estratégias. Ajuda às crianças de baixa tolerância à frustração a lidarem melhor com seus sentimentos.

- Brincadeiras de teatro com o uso de fantoches: O objetivo é propiciar o desenvolvimento da criatividade, da linguagem e da expressão corporal.

- Espumas coloridas: O objetivo desta atividade é trabalhar a percepção, os sentimentos, as emoções e a criatividade. Após colocar água e detergente em um recipiente, deverá ser feita bastante espuma e, sobre esta, acrescentar várias cores de anilina. Em seguida, uma folha branca de papel deve ser colocada sobre a espuma com o objetivo de tingir o papel. Depois, levanta-se a discussão do por que determinadas escolhas, de cor, desenho ou frase.

O uso e desenvolvimento de determinados exemplos de atividades arte terapêuticas serão responsáveis por proporcionar experiências estéticas que trazem a memória lembranças de momentos esquecidos, choros contidos, dores sufocadas, alegrias adormecidas, potenciais desconhecidos ou ignorados, caminhos não trilhados, conquistas e sonhos a serem atingidos. De acordo com Coll, Palacios e Marchesi (1995), A arteterapia possibilita ao indivíduo dialogar com sua própria interioridade, percebendo que é possível criar o novo e o belo tanto na arte, quanto na vida. 


\section{CONSIDERAÇÕES FINAIS}

O presente estudo teve como objetivo discutir a importância do professor de arte e a inserção de práticas terapêuticas para alunos público alvo da educação especial. Destacou-se que, ao estimular diversas funções e habilidades, as práticas artísticas/terapêuticas podem ser inseridas na educação especial com o propósito de perceber as habilidades e necessidades de cada educando, para que seja possível fazer as adaptações aos recursos e estratégias de ensino e, assim, facilitar e propiciar a aprendizagem.

A literatura existente em arte e educação tem apontado a importância da adaptação e adequação de recursos e estratégias para o ensino do aluno com deficiência. A disciplina de arte, juntamente com as demais, devem adaptar seus currículos para que possam receber alunos com deficiência com o desígnio de atendê-los de forma digna e eficaz. São inúmeros os discursos que constituem a escola e seu currículo no sentido de adequá-los a nova legislação e a nova realidade social que se impõe. O desafio que se coloca para os educadores é construir um espaço escolar onde a diferença, de qualquer natureza, possa "existir".

Ao mesmo tempo em que se preza pela inclusão dos alunos público alvo da educação especial, faz-se necessário refletir e reestruturar a formação daqueles que serão os principais responsáveis por essa inserção do aluno PAEE dentro das escolas regulares, ou seja, repensar a prática pedagógica do professor. Se esse profissional não acreditar no valor e na importância de sua atuação, se ele não se sentir capaz de promover uma transformação, por menor que seja, a possibilidade de ele realizar um atendimento educacional promotor de processos de ensino/aprendizagem será menor. Cabe aos professores, bem como, a comunidade escolar, de forma geral, se adaptar a realidade que estão inseridos, buscando cursos de formação complementar e capacitação para que possam aprimorar suas práticas educacionais no intuito de atender a demanda da expansão da educação especial.

São por estes motivos que dentro das escolas, visando contemplar a educação inclusiva, seria importante ter um profissional da área de artes capacitado para trabalhar técnicas artísticas baseadas no conceito da arteterapia. Além de ensinar os conteúdos préestabelecidos da disciplina e experimentar diferentes materiais e linguagens, este docente poderia contribuir para que os educandos possam expressar, por meio de modalidades 
artísticas diversificadas, seus conflitos interiores, na tentativa de superá-los e obter uma melhor qualidade de vida.

A proposta deste trabalho foi ampliar o diálogo existente entre a importância da arte e das práticas artístico terapêuticas para a educação inclusiva. Neste sentido, recomendam-se futuros estudos, realizados tanto por pesquisadores quanto por artistas plásticos e professores de arte, de modo a ampliar o entendimento a respeito da relação entre educação inclusiva e arte.

\section{REFERÊNCIAS}

ALLESSANDRINI, Cristina Dias. Analise micro genética da oficina criativa: projeto de modelagem em argila. São Paulo: Casa do Psicólogo, 2004.

BARBOSA, AnaMae (Org.).Arte educação: leitura no subsolo.4. ed. São Paulo: Cortez, 2005.

BOATO, Elvio Marcos. A caminho de um ensino mais que especial. São Paulo: Casa do Psicólogo, 2007.

BRASIL. Ministério da Educação. Diretrizes nacionais para a educação especial na educação básica. Brasília: MEC; SEESP, 2001.

BRASIL. Ministério da Educação. Saberes e práticas da inclusão: recomendações para a construção de escolas inclusivas. 2. ed. Brasília: MEC, Secretaria de Educação Especial, 2006. (Série Saberes e práticas da inclusão).

BRASIL. Ministério da Educação. Secretaria de Educação Fundamental. Parâmetros Curriculares nacionais: arte. Brasília: MEC; SEF, 1997.

CARDOSO, Maria Cecília de Freitas. Adaptando o conteúdo utilizando grandes áreas curriculares. Brasília: Corde, 1997.

CIORNAI, Selma. Percursos em arteterapia. São Paulo: Summus, 2004.

COLL, Cesar; PALACIOS, Jesus; MARCHESI, Alvaro. Desenvolvimento psicológico e educação. Porto Alegre. Artes Médicas, 1995.

COSTA, Robson Xavier da. A socialização do portador de deficiência mental através da arte. Revista Integração, Brasília, ano 12, ed. esp., p. 16-19, 2000.

DECLARAÇÃO DE SALAMANCA: Sobre princípios, políticas e práticas na área das necessidades educativas especiais. Salamanca-Espanha, 1994

EFLAND, Arthur. Cultura, sociedade, arte e educação num mundo pós-moderno. In: BARBOSA, Ana Mae; GUINSBURG, Jacó (Org.). O pós-modernismo. São Paulo: Perspectiva, 2005. p. 173-188. 
FERNANDES, Alícia. A inteligência aprisionada. Porto Alegre: Artmed, 1990.

FERREIRA, J. R.; GLAT, R. Reformas educacionais pós-LDB: a inclusão do aluno com necessidades especiais no contexto da municipalização. In: SOUZA, Donaldo Bello de; FARIA, Lia Ciomar Macedo de. (Org.). Descentralização, municipalização e financiamento da Educação no Brasil pós-LDB. Rio de Janeiro: DP\&A, 2003. p. 372- 390.

GOLDSCHMIDT, Lindomar. Sonhar, pensar e criar. Rio de Janeiro: Wak, 2004.

GUATTARI, Felix. CAOSMOSE: um novo paradigma estético. Rio de Janeiro: Ed. 34, 1992.

Lei de Diretrizes e Bases da Educação Nacional (LDB), Lei n2 9394 de 1996.

LIEBMANN, Marian. Exercícios da arte para grupos. São Paulo: Summus, 1994.

MAZZOTA, Marcos J. S. Educação especial no Brasil: história e políticas públicas. 4. ed. São Paulo: Cortez, 2003.

OMOTE, Sadao. A formação do professor de educação especial na perspectiva da inclusão. In BARBOSA, Raquel Lazzari Leite. Formação de educadores: desafios e perspectivas. São Paulo: Editora UNESP. 2003. p. 153-170.

ONU. Declaração de Salamanca. Espanha 1994. Disponível em: $<$ http://portal.mec.gov.br/seesp/arquivos/pdf/salamanca.pdf $>$. Acesso em: 24 out. 2015.

ORTIZ, Luciana Guedes Machado. Capacitando professores de ensino fundamental em serviço para uma educação inclusiva. Dissertação (Mestrado em Educação Especial) - Universidade Federal de São Carlos, São Paulo, 2003.

PROENÇA, Graça. História da arte. São Paulo: Ática, 2000.

READ, Herbert. O Sentido da arte. 3. ed. São Paulo: Ibrasa, 1976.

RUTZ, Tais B. Educação inclusiva e ensino de arte, percalços entre teoria e prática. 2010. $27 \mathrm{f}$. Trabalho de Conclusão de Curso (Graduação: Licenciatura em Artes Visuais) - Instituto de Artes Visuais, Universidade Federal de Pelotas, Pelotas.

SILVA, Silvia Maria Cintra da. Psicologia escolar e arte: uma proposta para a formação e atuação profissional. Campinas: Alínea; Uberlândia: Ed. Universidade Federal de Uberlândia, 2005.

SILVEIRA, Nise. O mundo das imagens. São Paulo: Ática, 2001.

URRUTIGARAY, Maria Cristina. Arteterapia e transformação pessoal pelas imagens. 2. ed. Rio de Janeiro: Wak, 2004.

VYGOTSKY, Lev S. Psicologia pedagógica. São Paulo: Martins Fontes, 1984. 